\title{
The Effect of Rootstock Cultivar and Bud Load on the Colour of Vitis vinifera L. cv. Muscat noir (Red Muscadel) Grapes
}

\author{
J.J. Hunter and A. C. de La Harpe \\ Viticultural and Oenological Research Institute, Private Bag X5026, 7600 Stellenbosch, Republic of South Africa.
}

Submitted for publication: September 1986

Accepted for publication: February 1987

Keywords: Vitis vinifera, rootstock, bud load, grape colour

\begin{abstract}
The effects of rootstock cultivar and bud load on colour expression in the grapes of Vitis vinifera L. cv. Muscat noir were investigated. Different rootstocks had no significant effect on skin colour density of the grapes. Grapes from vines with a low bud load (16 buds.vine ${ }^{-1}$ ) had the highest skin colour density.
\end{abstract}

The phenolic compounds in grapes are considered the most significant source of differences in flavour as well as colour among white, rose and red wines. They include the natural ingredients of wine which react with oxygen and are crucial to its preservation, maturation and ageing (Singleton, 1982). The phenolic compounds of red grapes are constituted mainly of anthocyanins and tannins, both of which play a preponderant and well-known role in the organoleptic character (colour and taste) of red wines (Ribéreau-Gayon \& Glories, 1982).

According to Singleton \& Esau (1969), the seeds of white grapes contain the largest quantity of phenolic compounds, while the skins of red and black grapes also contain these compounds in considerable quantities. Pirie \& Mullins (1980) consider the skin as the most important source of phenolics extracted from the grape berry during the vinification of red wine. Hrazdina \& Moskowitz (1982) found the anthocyanin pigments to be localized in the outermost epidermal cells, reaching about six cell layers into the berry. In most $\mathrm{Vi}$ tis vinifera cultivars only the 3-glucosides of the commonly occurring anthocyanidins, namely cyanidin, peonidin, delphinidin, petunidin and malvidin are found (Singleton, 1982).

It is generally accepted that overcropping induces inferior grape quality for both table use and wine making. Weaver, Amerine \& Winkler (1957) found grapes of overcropped vines of Alicante Bouschet, Carignane, Petit Sirah (Durif), Pinot Pernand and Zinfandel (mean 7,76; 7,37; 8,64; 4,31; 12,07 kg.vine ${ }^{-1}$, respectively) to have less colour, delayed maturation and a lower percentage of available sugars and starch. They also found that wines made from lightly cropped vines (mean 3,86; 3,72; 4,92; 2,43; 8,36 kg.vine ${ }^{-1}$, respectively) usually scored highest during sensory evaluation. According to Winkler (1964) overcropping of Tokay and Emperor vines (30 and 20 buds.vine ${ }^{-1}$, respectively) had a detrimental effect on the compositional balance of the fruit as well as the flavour, colour, texture and character of the wine produced. Contrary to this, Ough \& Nagaoka (1984) found that crop thinning had a minimal effect on wine quality for Cabernet Sauvignon (both heat treated and not heat treated) on its own roots and grafted to Rupestris St George rootstock (not heat treated) and at three different localities. However, locality (as differentiated by rootstock and virus status) had a considerable effect on colour, as well as phenolic and potassium content. Ough, Cook \& Lider (1968) came to the conclusion that the choice of rootstock for a specific vine alters the juice composition significantly. Changes in the colour characteristics of the skin can therefore also be induced.

South African wines made from the grapes of $V$. vinifera L. cv. Muscat noir generally tend to lack colour. It seems to be influenced by climatic factors, rootstock, and crop load. This investigation therefore deals with the effect of rootstock and bud load on grape colour.

\section{MATERIALS AND METHODS}

\section{Experimental vineyard:}

An eleven year old Vitis vinifera L. cv. Muscat noir vineyard situated at Robertson experimental farm in the Cape Province was used for this experiment. The cultivar was grafted onto six different rootstock cultivars, namely 101-14 Millardet et de Grasset ( $V$. riparia Michx. x $V$. rupestris Scheele), 99 Richter ( $V$. Berlandieri Planch. $\mathrm{x} V$. rupestris), 110 Richter $(V$. Berlandieri $\mathrm{x} V$. rupestris), $V$. champini var. Ramsey, $V$. rupestris $\mathrm{cv}$. Constantia Metallica and $V$. rupestris $\mathrm{cv}$. Rupestris du Lot. Vines were grown on a Hutton soil and trained onto an extended double Perold trellising system as described by Zeeman (1981). Depending on the weather conditions, sprinkler irrigation at approximately $80 \mathrm{~mm}$ per month was applied.

\section{Experimental design:}

The experimental vineyard was laid out in a split-plot design. Six rootstock cultivars (main plots) were randomly allocated to each of three replicate blocks. Four treatments $(16,24,32$ and 40 buds per vine), each comprising five visually homogeneous vines, were applied per rootstock.

\section{Analytical procedures:}

Grapes were harvested during two consecutive seasons (1983/'84 and 1984/'85). All bunches of each subplot were harvested at $24^{\circ} \mathrm{B}$ and stored at $20^{\circ} \mathrm{C}$ until required. A hundred berries per subplot were randomly sampled. The skins were separated from the pulp by gentle squeezing between thumb and forefinger. They were then blotted dry with paper towels and the fresh mass determined. The skins were macerated in $250 \mathrm{~cm}^{3}$ boiling methanol for three minutes using a mechanical 
homogeniser. The homogenate was centrifuged for 20 minutes at $13218 \mathrm{~g}$, the supernatant decanted, the residue resuspended with $250 \mathrm{~cm}^{3} 80 \%$ methanol and the procedure repeated. Supernatants were combined, diluted to $1000 \mathrm{~cm}^{3}$ with methanol and a $50 \mathrm{~cm}^{3}$ aliquot extracted $(3 \mathrm{x})$ with equal volumes of hexane in a separatory funnel and the hexane extracts discarded. The resultant methanolic aliquot was then made up to $50 \mathrm{~cm}^{3}$ and adjusted to $\mathrm{pH} 5,0$ using $1 \mathrm{M} \mathrm{HCl}$ and $1 \mathrm{M} \mathrm{NaOH}$.

Specific skin colour density was spectrophotometrically determined as $\mathrm{A}_{420}+\mathrm{A}_{520}$ as described by Somers \& Evans (1977). Results were expressed as absorbance units per $\mathrm{kg}$ fresh mass of skins.

\section{Statistical analyses:}

Statistical analyses to test significant differences among treatment means were done using a BMDP statistical software package (Dixon et al., 1983).

\section{RESULTS AND DISCUSSION}

Preliminary trials showed that colour data obtained with the extraction method used in this study correlated well with the colour intensity of wines made from the same grapes (data not shown). The effect of rootstock cultivar and bud load on specific skin colour density of Muscat noir grapes in the two consecutive seasons is presented in Fig. $1 \& 2$. Because no significant interactions between cultivars and bud loads were found within the different seasons, only the main effects of cultivars and bud loads were considered.

\section{Effect of rootstock:}

The different rootstocks investigated did not differ significantly in their effect on skin colour density of
Muscat noir grapes in either of the seasons $(P=0,14$ and $\mathrm{P}=0,23$ respectively) (Fig. 3 ). This is in contrast to the findings of Ough \& Nagaoka (1984) that rootstock has a considerable effect on colour of Cabernet Sauvignon grapes. However, Ough, Cook \& Lider (1968), investigating ten different wine grape cultivars on Rupestris St George and 99 Richter, at normal and high $\mathrm{NH}_{4} \mathrm{NO}_{3}$ fertilizer levels, also found no effect on colour expression in the grapes. Although it would seem that different rootstocks did not affect skin colour density of Muscat noir grapes in the Robertson region, it is, however, possible that differences may occur in regions where other climatic and soil conditions exist.

\section{Effect of bud load:}

Compared to the other bud load treatments, the 16 bud load treatment had a significantly higher skin colour density over all cultivars during the 1983/' 84 season $(\mathrm{P}<0,01)$ (Fig. 4). Bud loads of 16, 24, 32 and 40 are comparable to $14,17,19$ and 21 t.ha $^{-1}$, respectively (G W Fouché, 1985, unpublished data). Different bud loads during the 1984/'85 season, however, resulted in no statistical differences between bud loads $(\mathrm{P}=0,32)$ over all rootstock cultivars $(\mathrm{P}=0,23)$.

Considering the data of the two seasons, it seems that skin colour density in the second season was generally higher than that of the foregoing season. Along with the fact that no statistical differences could be obtained in the second season, this anomaly may have resulted from the well documented influence of environmental factors such as temperature, light intensity, soil moisture content and plant nutrient level on red colour expression in grapes (Weaver \& McCune, 1960; Weaver,

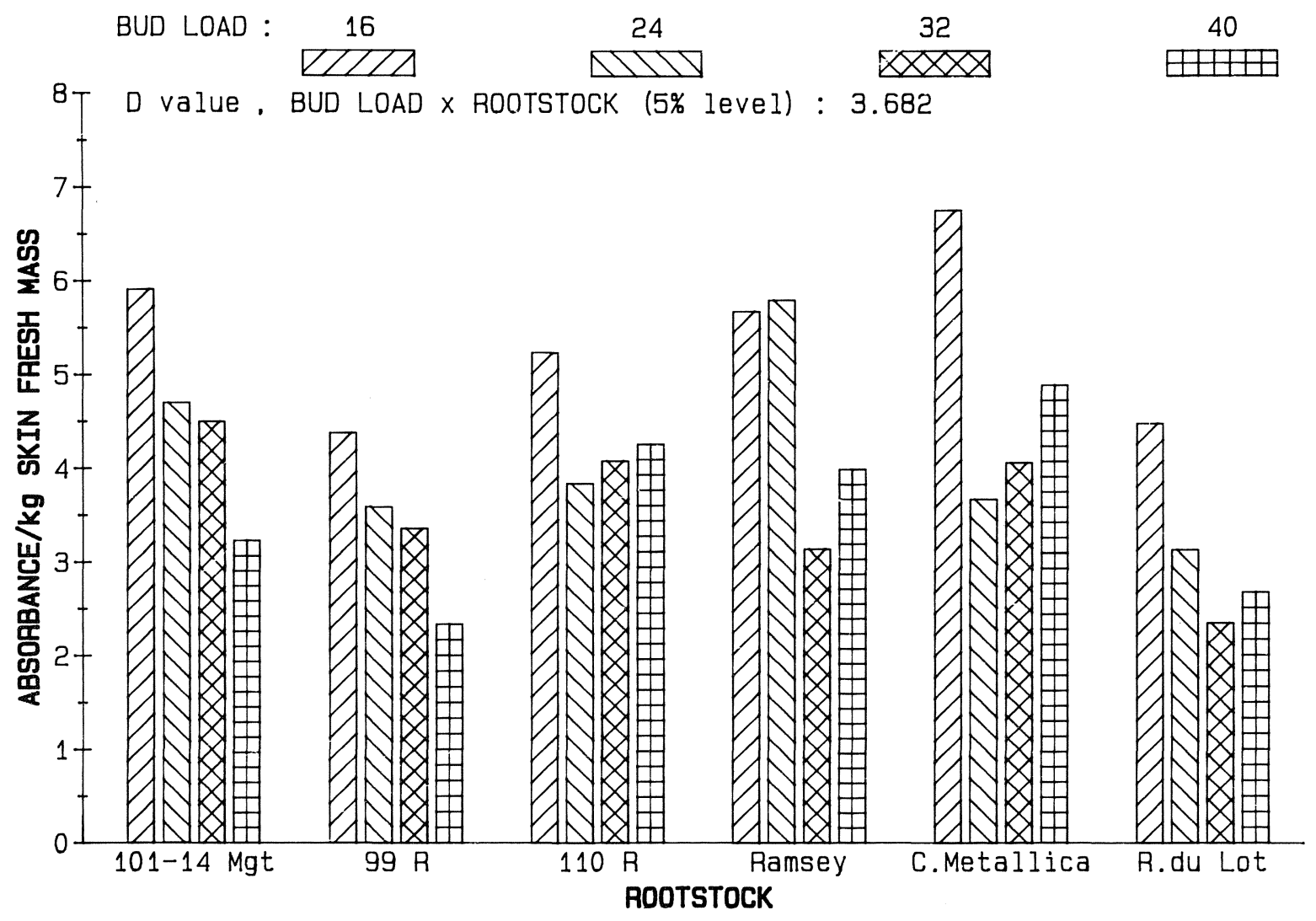

FIG. 1

Effect of rootstock cultivar and bud load on skin colour density of Muscat noir grapes (1983'84). 


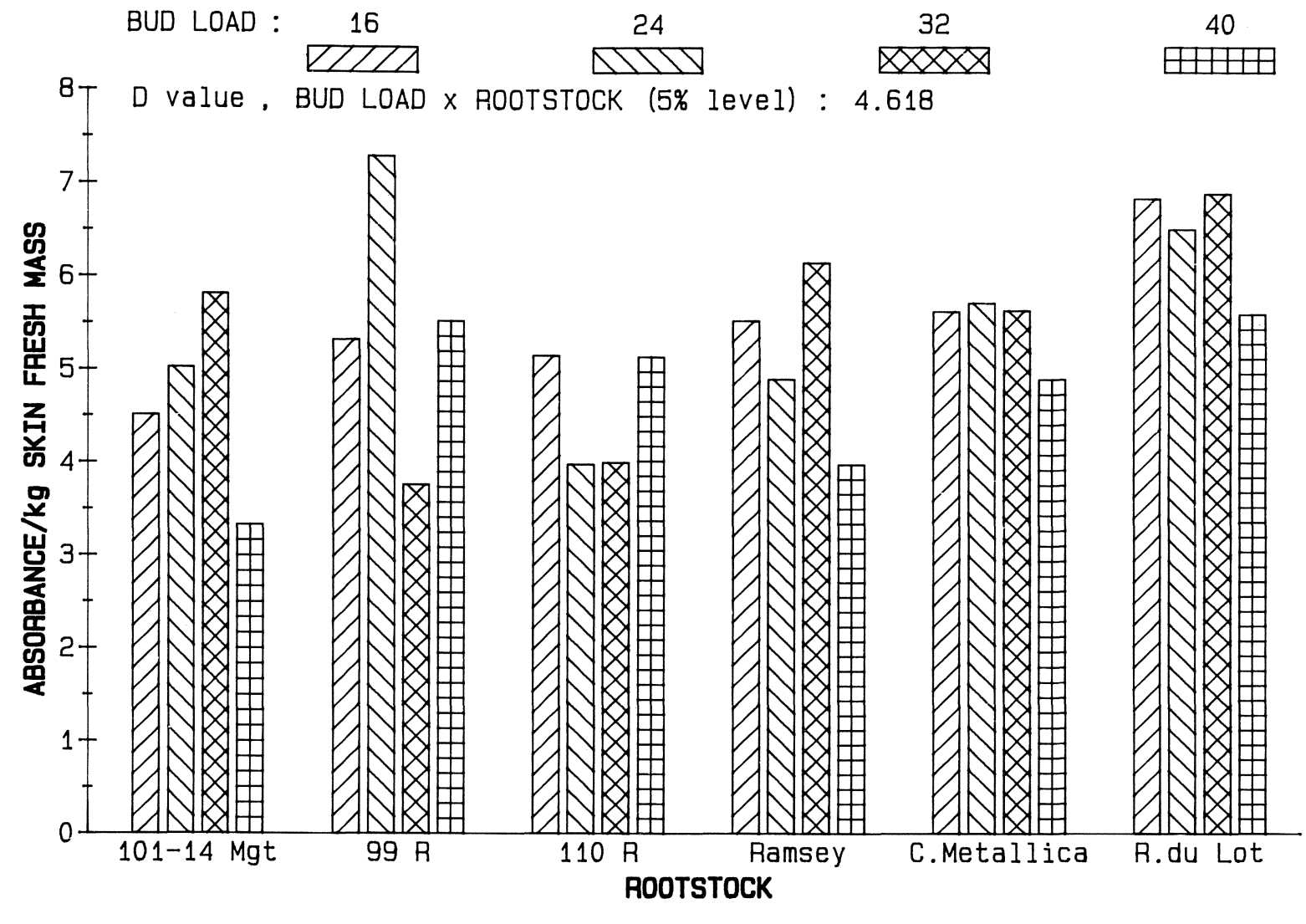

FIG. 2

Effect of rootstock cultivar and bud load on skin colour density of Muscat noir grapes (1984'85).

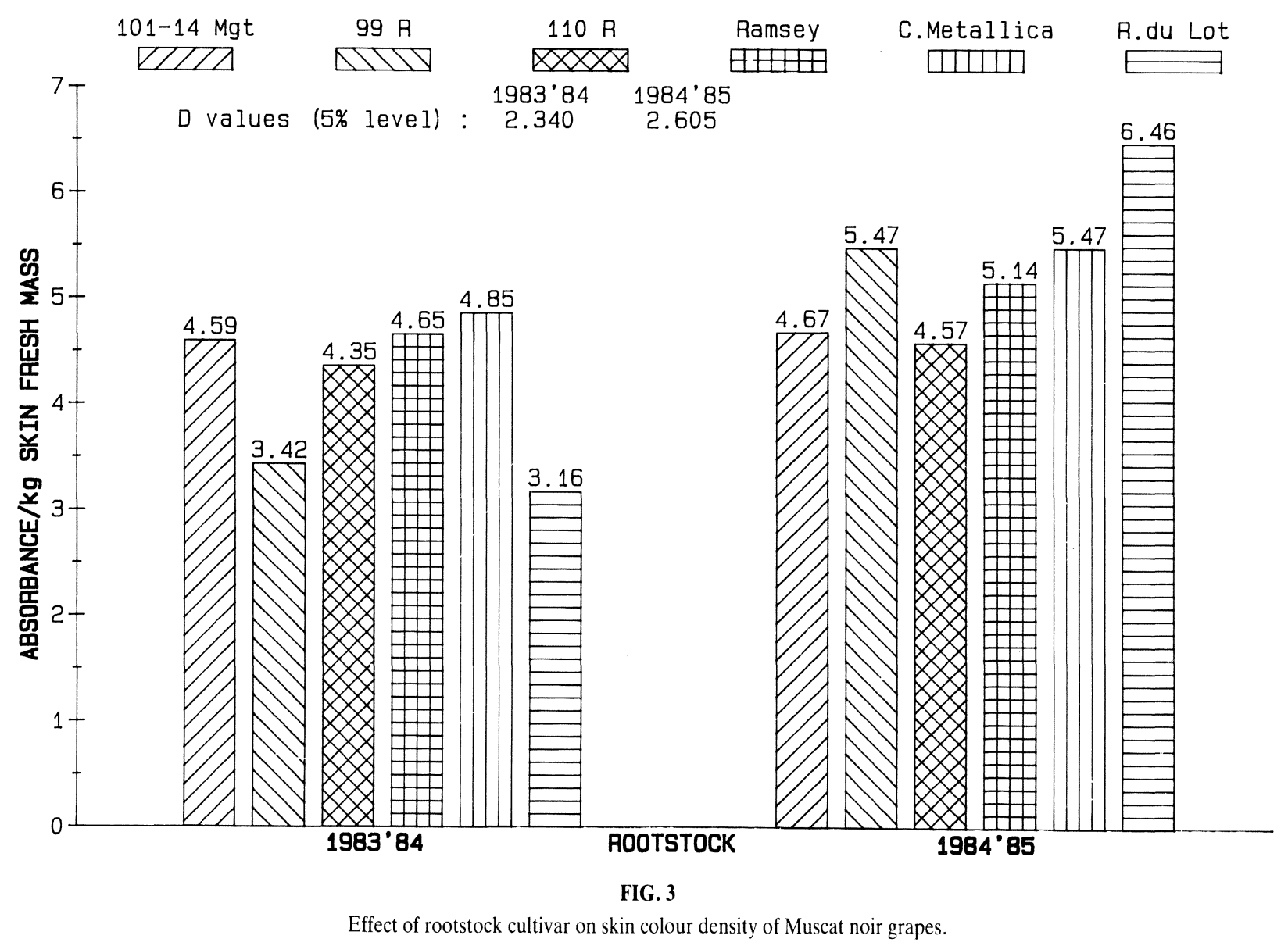


1963; Kliewer, 1970; Kliewer, 1977; Pirie \& Mullins, 1977; Wicks \& Kliewer, 1983; Hrazdina, Parsons \& Mattick, 1984).

The 1983/'84 bud load effects are in agreement with the findings of several investigators (Weaver, Amerine \& Winkler, 1957; Weaver, McCune \& Amerine, 1962; Winkler, 1964; Pirie, 1979; G W Fouché 1985, unpublished data) on a variety of cultivars which indicate that overcropping of vines is detrimental to grape quality.

\section{CONCLUSIONS}

It is evident that the rootstocks investigated did not affect skin colour density of the grapes in the Robert- son area. However, colour density was differently affected when different bud loads were applied to Muscat noir grafted onto various rootstocks. The overall impression is that the 16 bud load treatment can be considered the most acceptable for colour expression in Muscat noir grapes, irrespective of rootstock cultivar.

However, it appears that environmental conditions in a certain season can have a great effect on the colour of Muscat noir grapes thereby complicating recommendations regarding application of a certain bud load. In order to verify the results, this investigation should be repeated under controlled conditions.

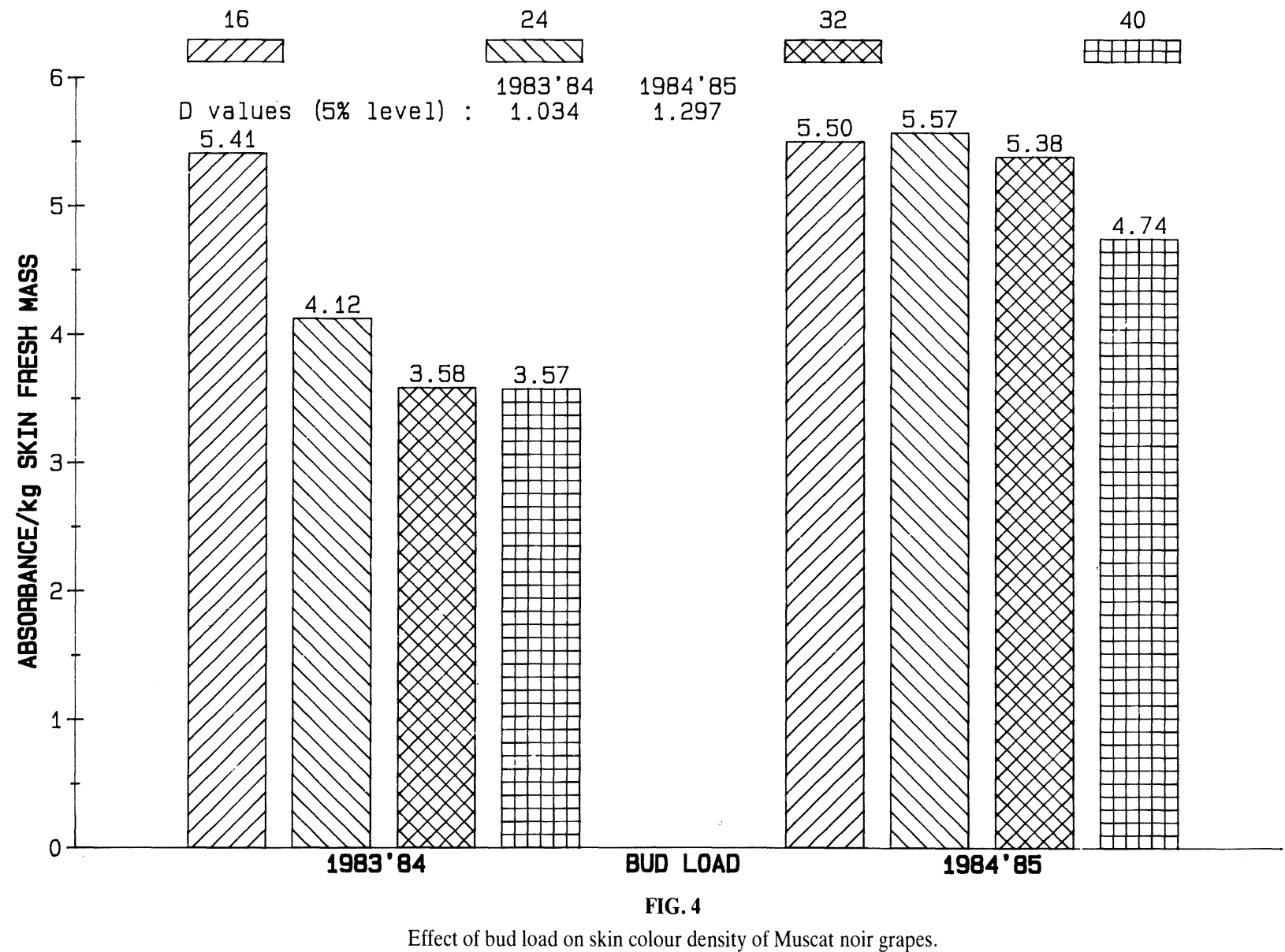

LITERATURE CITED

DIXON, W.J., BROWN, M.B, ENGELMAN, L, FRANE, J.W HILL, M.A., JENNRICH, R.I. \& TOPOLAREK, J.D., 1983. BMDP Statistical software. University of California Press. London.

HRAZDINA, G. \& MOSKOWITZ, A.H., 1982. Subcellular status of anthocyanins in grape skins. In: Grape and Wine Centennial Symp. Proc., 245-253. University of California, Davis.

HRAZDINA, G., PARSONS, G.F. \& MATTICK, L.R., 1984. Physiological and biochemical events during development and maturation of grape berries. Am. J. Enol. Vitic. 35, 220-227.
KLIEWER, W.M., 1970. Effect of day temperature and light intensity on coloration of Vitis vinifera L. grapes. J. Amer. Soc. Hort. Sci. 95, 693-697.

KLIEWER, W.M., 1977. Influence of temperature, solar radiation and nitrogen on coloration and composition of Emperor grapes. Am. J. Enol. Vitic. 28, 96-103.

OUGH, C.S., COOK, J.A. \& LIDER, L.A., 1968. Rootstock-scion interactions concerning wine making. II. Wine compositional and sensory changes attributed to rootstock and fertilizer level differences. Am. J. Enol. Vitic. 19, 254-265. 
OUGH, C.S. \& NAGAOKA, R., 1984. Effect of cluster thinning and vineyard yields on grape and wine composition and wine quality of Cabernet Sauvignon. Am. J. Enol. Vitic. 35, 30-34.

PIRIE, A., 1979. Red pigment content of wine grapes. Australian Grapegrower and Winemaker 189, 10-12.

PIRIE, A. \& MULLINS, M.G., 1977. Interrelationships of sugars, anthocyanins, total phenols and dry weight in the skin of grape berries during ripening. Am. J. Enol. Vitic. 28, 204-209.

PIRIE, A. \& MULLINS, M.G., 1980. Changes in anthocyanin and phenolics content of grapevine leaf and fruit tissues treated with sucrose, nitrate, and abscisic acid. Plant Physiol. 58, 468-472.

RIBÉREAU-GAYON, P. \& GLORIES, Y., 1982. Structure of condensed phenolic compounds in vinifera grapes and wine. Influence of ripening and infection by Botrytis cinera on phenolic content. In: Grape and Wine Centennial Symp. Proc., 228-234. University of California, Davis.

SINGLETON, V.L., 1982. Grape and wine phenolics; background and prospects. In: Grape and Wine Centennial Symp. Proc., 215227. University of California, Davis.

SINGLETON, V.L. \& ESAU, P., 1969. Phenolic substances in grapes and wine and their significance. Academic Press, New York and London.
SOMERS, T.C. \& EVANS, M.E., 1977. Spectral evaluation of young red wines: anthocyanin equilibria, total phenolics, free and molecular $\mathrm{SO}_{2}$, "chemical age". J. Sci. Fd. Agric. 28, 279287.

WEAVER, R.J., 1963. Effect of leaf to fruit ratio on fruit quality and shoot development in Carignane and Zinfandel wine grapes. Am. J. Enol. Vitic. 14, 1-12.

WEAVER, R.J., AMERINE, M.A. \& WINKLER, A.J., 1957. Preliminary report on effect of level of crop on development of color in certain red wine grapes. Am. J. Enol. Vitic. 8, 157-166.

WEAVER, R.J. \& McCUNE, S.B., 1960. Influence of light on color development in Vitis vinifera grapes. Am. J. Enol. Vitic. 11, 179184.

WEAVER, R.J., McCUNE, S.B. \& AMERINE, M.A., 1962. Effect of level of crop on vine behaviour and wine composition in Carignane and Grenache grapes. Am. J. Enol. Vitic. 12, 175-184.

WICKS, A.S. \& KLIEWER, W.M., 1983. Further investigations into the relationship between anthocyanins, phenolics and soluble carbohydrates in grape berry skins. Am. J. Enol Vitic. 34, 114-116.

WINKLER, A.J., 1964. Effects of overcropping. Am. J. Enol. Vitic. 5, 4-12.

ZEEMAN, A.S., 1981. Oplei. In: Wingerdbou in Suid-Afrika, 185201. J.D. Burger \& J. Deist (Eds.). VORI, Stellenbosch. 